\title{
MECHATRONIC SYSTEM FOR DRYING HUMAN BODY AFTER BATH
}

\author{
Luís Atilano ${ }^{1}$, Carlos Grenha ${ }^{2}$ \\ 1,2 Department of Mechanical Engineering, School of Engineering, University of Minho, \\ Campus of Azurém, 4800-058 Guimarães, Portugal \\ pg32955@alunos.uminho.pt,pg32959@alunos.uminho.pt
}

\begin{abstract}
From several tasks needed for taking care of disabled and/or bedridden people, bath is one of them. After bath, of those persons, one of most important tasks is related with during the human body, mainly in users with reduced mobility. Those users need some specific assisting devices that can help them performing drying their own body after bath. Existing devices, for those purposes are not satisfying those people for several reasons that are explained on this paper. The main added value of this paper is the proposition of a mechatronic device for performing those tasks, related with human body drying, and covering some gaps detected when other similar systems have been analysed. An equipment, for being attractive in this domain, must combine three main requirements: comfort, efficiency and safety. Those three characteristics were always taken in consideration during the design of the proposed solution. That solution is presented in this paper as a future and it is expected that can to solve the majority of the identified problems in the mentioned context. A conceptual model of the proposed solution is presented.
\end{abstract}

Keywords: Wellbeing, Disabled people, Conceptual modelling, Drying device, Mechatronic system

\section{Introduction}

Assistive devices for helping disabled, elderly and/or bedridden persons is a subject that is being studied from several years ago, in order to improve wellbeing for those persons due to demographic and social evolution of societies, mainly in developed countries [1].

There are two main groups of equipment and devices that can be developed for assisting mentioned groups of persons: the information systems that the mechatronic/mechanical systems.

For the information systems, it is possible to use some, more or less traditional configurations for communicating on the environment, where are placed those persons, [2,3] or exchanging communication from inside of the environment to doctors, or caregivers, by using communication networks and communication systems that are usually very efficient for those tasks [4]. In some critical applications, some analysis techniques [5-9] of the used controllers can be used, as in the case of critical systems for other applications.

Concerning mechatronic/mechanical systems, several aspects have been studied and some solutions have been presented in some domains, such as on the domain of transferring people from a position to another [10] or developing specific systems for assisting bath of bedridden persons [11].
After analysing some domains in which some devices have been developed, it seems that one existing gap concerns the existence of devoted devices for drying human body after bath. In this field, the solutions are not adequate neither adapted to specific needs of potential users. In this paper, it is proposed a solution for a mechatronic device for this purpose and a conceptual model is presented.

In order to achieve the main goal proposed for this work, the paper is organized as follows: section 2 describes the state of the art about existing drying devices for human body, after bath; section 3 presents the main requirements for a system of this kind and proposes a possible solution for satisfying those requirements; section 4 discusses the main obtained results; and, finally, section 5 presents some conclusions and future work in this domain.

\section{State of the Art}

In addition to benchmarking on similar products/solutions, was imperative a bibliographical review of a several patents. Highlighting the most relevant topics of this analysis:

Figure 1a) shows The Body Dryer [12]. This product was never marketed officially, however, it was conceived as part of a campaign of a crowdfunding platform Indiegogo. The idea of this product was based on the emission (from the bottom up) of ionized air from a platform that could be applied to any soil. Despite the pre-sales and the generation of almost three hundred thousand euros 
of investment, the promoter of this product could not move forward with the project.

Figure $1 \mathrm{~b}$ ) shows the Care Dryer, a product produced by Haystack Dryers, which is dedicated to recreational body dryers and body dryers for geriatric and supportive activities. The products produced by this company have the peculiarity of being customized and the solution is always thought on a case by case basis according to the needs of the client. Of course, this customized support has a significant influence on price, delivery time and the need to include technicians both during the product development and the installation.

Figure 1c) shows the Tornado Body Dryer, a product characterized by the application in the shower and the principle of operation is based on the emission of hot air to the body through holes in the structure. Some of the problems reported by users relate to the low flexibility of the equipment (it can only be installed on a flat vertical wall) and the absence of a preheating, which implies receiving a cold flow at the beginning of each operation.

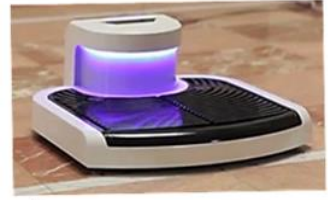

a)

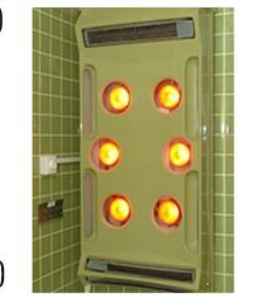

c)

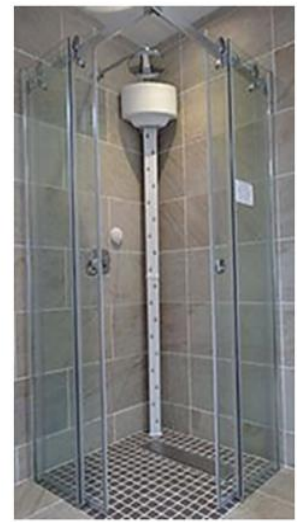

Figure 1: a) The Body Dryer; b) Care Dryer; c) Tornado Body Dryer [12-14]

Regarding patent review, we found a lot of diversity focusing on solving a specific problem. Not being at all versatile regarding a general solution.

CN1547446 - Based on ventilated air jets front to the user, mounting on a vertical rail allows you to adjust the height. It has the disadvantages of being a fixed structure on the wall and does not solve the problem of bedridden patients [15].

GB2497798 - It bases its operation on air jets in three vertical tubes in order to increase the drying area. It has a proximity sensor to activate the system. It has disadvantages of high required space and does not solve the problem of bedridden patients [16].

US4970736 - It is an ideal integrated solution for drying bedridden patients, but otherwise does not solve the problem of ordinary household users. It presents as disadvantages the high complexity, which leads to a difficult assembly [17].

US5930912 - It bases the operation on ventilated air jets through three tubes positioned in specific positions to dry the front and the back of the user. It has the advantage of being collapsible, facilitating portability. However, when assembled it entails a high general overlap and does not solve the problem of bedridden patients [18].

US6148539 - It is based on the operation of air jets implying high overall dimensions due to the geometry being a dome. It is not collapsible, so you cannot fix it. Another disadvantage is not solving the problem of bedridden patients [19].

US20070039199 - System adaptable to a common shower, mounted on the shower area. It promotes a drying only over the user and may imply the need to resort to skilled labor in adapting the system. Other disadvantages are limited portability and do not solve the problem of drying bedridden patients [20].

US2060331193 - It is characterized by a hose adaptable to a common shower when connected to a fan. It is based on an air jet and has the advantages of being flexible enough to aid drying in more localized areas. As disadvantage has the low drying efficiency [21].

The analysis of competition and the review of patents were fundamental inputs in the development of the project. The system is presented with a mixture of several components in a new and more complete solution.

Therefore, a new solution was designed based on versatility, comfort and efficiency.

\section{System Development}

The design methodology covers all the techniques, procedures and 'tools' that the designer can use in combination to achieve a specific goal within a welldefined deadline [22].

Therefore, our idea came up in an approach composed of six phases, where each one will be composed by internal stages.

During the project, eight important aspects were assumed as required (Table 1):

Table 1 - Project requirements

\begin{tabular}{|l|}
\hline $\begin{array}{l}\text { Capacity to ventilate air at } 40{ }^{\circ} \mathrm{C} \text { after } 30 \\
\text { seconds; }\end{array}$ \\
\hline Maximum air speed of about $10 \mathrm{~m} / \mathrm{s} ;$ \\
\hline $\begin{array}{l}\text { Structure in innocuous materials to allow an } \\
\text { easy cleaning; }\end{array}$ \\
\hline $\begin{array}{l}\text { Capacity to support bending tensions caused } \\
\text { by a user with } 120 \mathrm{~kg} ;\end{array}$ \\
\hline Easy sanitation of all the exposed components; \\
\hline Possibility to choose temperature; \\
\hline Parameters controlled by the user; \\
\hline Poka-Yoke mounting sequence; \\
\hline
\end{tabular}

Furthermore, some other characteristics were assumed as desirable but not required (Table 2): 
Table 2 - Project requirements desired

\begin{tabular}{|l|}
\hline $\begin{array}{l}\text { Possibility to ventilate from the room } \\
\text { temperature to } 35^{\circ} \mathrm{C}\end{array}$ \\
\hline $\begin{array}{l}\text { Capacity to execute a drying cycle in } 3,5 \\
\text { minutes }\end{array}$ \\
\hline $\begin{array}{l}\text { Dismiss the presence of a specialized technician } \\
\text { to do the installation }\end{array}$ \\
\hline Easy access and adaptability of the equipment \\
\hline Possibility to install in all the types of space \\
\hline Automatic switch off after one cycle \\
\hline
\end{tabular}

Figure 2 shows the proposed drying system. The main distinguishing factor of this system is the ability to dry users lying down, responding to the problem of drying bedridden patients; and dry users standing, covering the range of home users.

In the case of standing users (Figure 2a), the system has a telescopic tube allowing the appropriate height adjustment for each user. In addition, to prevent the user of pulling down the equipment while holding the knob, it is equipped with an anchor that must be activated at the rear of the system before the operation (without it the system will not turn on).

In the case of bedside users (Figure 2b), the system provides the functionality of turning the drying arm $90^{\circ}$, emitting infrared radiation and blowing hot air. In this mode of operation, the caregiver (it is assumed that bedridden users will require the assistance of a caregiver) will move the system along the body of the bedridden promoting the drying of the whole body.

During the benchmark analysis, one of the user complaints was related to the beginning of the operation on a ventilation based dryer. In fact, at the start, the heat resistance is not on the proper temperature so the user receives a wave of cold air that is uncomfortable and can cause health problems.

In both operating modes, the combined action of radiation and ventilation makes drying more efficient, allowing rapid body drying.

The option for a combined solution was linked to the increasing versatility of products and to increase the range of potential purchasers of the product, since it covers different market types (common users, elderly population and continued care). This would solve two problems faced by the elderly: danger of falling in case of climbing to some platform or step and the difficult drying of the back with the towel. a)
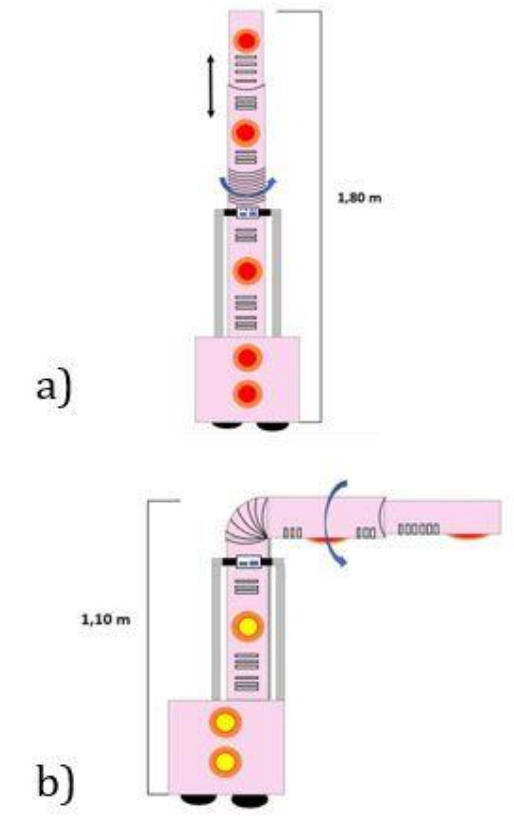

Figure 2: Schematic representation of the solution a) Mode A; b) Mode B

\section{- Operation modes}

Another aspect to highlight in the designed solution was the possibility of opting for the individual activation of radiation drying or ventilation, in addition to the predefined mode that considers the combination of both. It was thought that an even more customizable model could be applied by the operator, but it was considered that the four levels established and the possibility of free combination between the two integrated methods already allowed sufficient flexibility, avoiding a greater complexity of design in the development relating to the control system.

Regarding the operating modes, the premise in the creative phase was the versatility. Following the prior review of the state of the art, it has been found that existing solutions focus on solving very specific problems, and it is clearly advantageous to create a disruptive and ambivalent solution. This would achieve the best of both worlds: on one hand ensuring the resolution of the drying problem and on the other hand increasing the scalable potential by widening the market spectrum covered by the new product.

Due to this the projected solution will have two main operating modes, designated $A$ and $B$.

Mode A, Figure 2a), for the drying of common standing users, and mode B, Figure $2 \mathrm{~b}$ ), for the drying of bedridden patients.

In the case of mode A, vertical use by ordinary users, the lamps connect together with the electric resistance, as soon as the resistance heats the air it will be vented against the wet body, promoting drying through a combination of methods (radiation and ventilation). 
The intensity of the radiation and pressure of the ventilation will have a maximum limit of safety to avoid damages to the user and to guarantee comfort. It will be possible for the user to regulate the currents through the interface built into the system.

In case of mode $\mathrm{B}$, horizontal use for bedridden patients, only the upper lamps will work, since the rest would not perform useful work, besides the ventilation system. The caregiver who will support the bedridden patient will be responsible for positioning the system, moving it along the length of the patient as it is drying (it is assumed that 3 to 4 positions are required until complete drying). In the same way, the caregiver can regulate the system within a previously subdivided range of 4 levels of functioning, considering the specific safety limits for elderly bedridden patients.

It should be clarified that at any level the operator may choose to individually use one of the drying methods or a combination of the two. For example, level 0 for ventilation and 3 for radiation will only use the radiation as a drying method; Level 2 for ventilation and level 3 for radiation will cause the two methods to be combined. In the Figure 3, the control interface is represented.

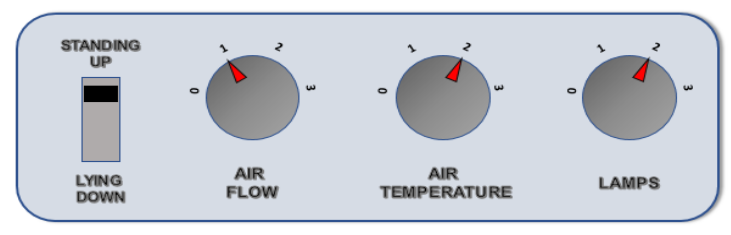

Figure 3: Representation of the control interface

The incorporation of a hose connectable to the system increases the flexibility in the drying process, allowing a more localized drying.

Considering the initial phase of analysis and optimization of the solution, it was important to dimension the ventilation system and the infrared radiation system.

The domestic power grid is limited to the single-phase mains and should not exceed $2500 \mathrm{~W}$. The drying/heating solutions almost always involve a high energy expenditure. For this reason, a power distribution by the main elements of the system was considered to achieve an energy balance that favors functional performance.

Figure 4 illustrates this power distribution, having allocated $1800 \mathrm{~W}$, with a division of $1600 \mathrm{~W}$ for electrical resistance, $600 \mathrm{~W}$ for infrared lamps, $200 \mathrm{~W}$ for the fan and the remainder for other components with lower energy requirements like the display.

$\begin{array}{ccc}\begin{array}{c}\text { Electric resistence } \\ (1600 \mathrm{~W})\end{array} & \text { Lamps } & \text { Fan } \\ (600 \mathrm{~W}) & (200 \mathrm{~W}) & \text { Others }\end{array}$

Figure 4: Distribution of power by different elements of the system

\section{- Pressurized air system}

The drying process presupposes a combination of ventilation and radiation. Therefore, it was necessary to dimension the equipment according to a fluid mechanics, so that not only the pressure of the air jets is adequate, but also a dimension and geometry of the grooves.

For this project, it was assumed that the subfunction of air ventilation may be similar to that used in electric bathroom hand dryers. Knowing that the area of the body is much superior to the area of the hands, it was chosen to aim the flow of air in the equipment at $440 \mathrm{~m}^{3} / \mathrm{h}$, about twice that of hand dryers.

Since it is a power available was limited, we can compromise between the airflow and the temperature increase that we want. On the other hand, a choice of fan and resistance is crucial to ensure the desired parameters in the most efficient way possible, maximizing system performance.

Starting from the power of $1800 \mathrm{~W}$ for this subsystem, we chose a division with $1600 \mathrm{~W}$ for the electrical resistance and $200 \mathrm{~W}$ for the fan. Thus, from a flow of $440 \mathrm{~m}^{3} / \mathrm{h}$, it was possible to heat the ventilated air at about $3{ }^{\circ} \mathrm{C}$.

As one of the objectives for this equipment was adaptability to each case, the ventilated flow and temperature rise of the ventilated air can be adjusted to different combinations of operation, obeying the condition that for a lower flow, with the same dissipated electric power on resistance, the increase in air temperature will be greater.

To achieve a maximum output velocity of $10 \mathrm{~m} / \mathrm{s}$, which ensures no damages on the user's skin, and considering $440 \mathrm{~m}^{3} / \mathrm{h}$ of flow, through the equation 1:

$$
Q=A \times v
$$

Where $Q$ represents the flow rate, $A$ represents the cross-sectional area and $v$ the fluid flow velocity, an area of $0.0122 \mathrm{~m}^{2}$ or $122 \mathrm{~cm}^{2}$ is obtained. By distributing the air outlets evenly over 150 linear centimeters corresponding to the height of the equipment $(30 \mathrm{~cm}$ for the curve and other elements were excluded), it was calculated that the width of exits will be $8 \mathrm{~mm}$, distributing the $8 \mathrm{~mm}$ total by 4 outlets of $2 \mathrm{~mm}$ wide each as shown in Figure 5.

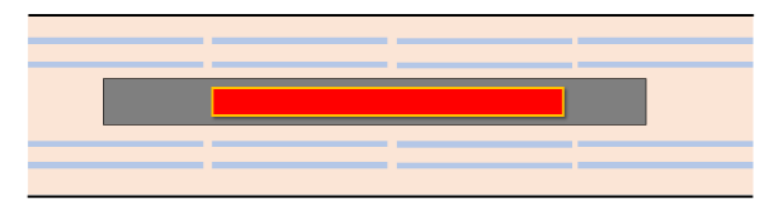

Figure 5: Schematic representation of the conjugation between longitudinal grooves and infrared lamp 
Regarding the expected fan pressure, considering that the design dryer does not include any filtration system and that therefore the only load losses will be caused by the length of the equipment, the constrictions in the air outlet and the curve (in mode B) led to opt for a dual-suction centrifugal lowpressure fan as shown in Figure 6.

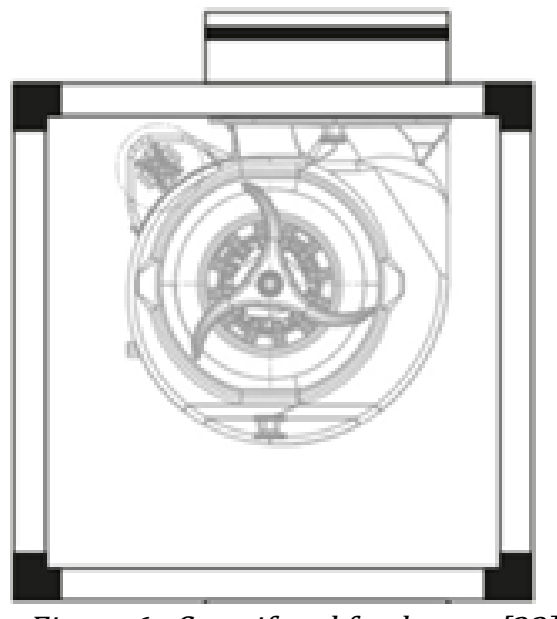

Figure 6: Centrifugal fan layout [23]

As usual in engineering the team started from the principle of comparison to theoretically predict the drying time using only ventilation. For this it was based on hand drying equipment present in several bathrooms. The reference drying time announced by most manufacturers is $10 \mathrm{~s}$ [24]. Comparing the hand area, about $0.0896 \mathrm{~m} 2$ [25], and the body area, about $1.8 \mathrm{~m} 2$ [26], and considering that the body dryer equipment has twice the flow rate of the hand dryer, the ventilation drying subsystem should be able to dry the body in $3,35 \mathrm{~min}$. Although if this time seems long, the effect of radiation should still be considered, which will reduce the drying time. It is ideal to achieve a minimum time of drying. But 3,35 min still below of $4 \mathrm{~min}$, which corresponds to the average time that an elderly person takes to dry, as measured by potential users.

\section{- Heat transfer by IR radiation}

Regarding the radiation drying component, it was important to check for any legal restrictions on infrared radiation. For this purpose, the standard NP EN 060335-2-27:2015, which follows the European Standard, and addresses the requirements for ultraviolet and infrared radiation devices for skin exposure home appliances was acquired from the Portuguese Quality Institute [27]. From the analysis made to the norm, the following points are highlighted, numerically listed by decision of the authors:

1. "Infrared transmitter (IR emitter) - Radiant source constructed to emit energy at wavelengths of $800 \mathrm{~nm}$ or higher."
2. "Apparatus with only IR emitters shall be tested as heating apparatus."

3. "Instructions for devices with IR emitters shall be provided with eye protection warnings against exposure to infrared radiation and a warning to take precautions to protect the user against the danger of overexposure."

The considerations in the standard emphasize the special care in the treaty in point 3 . It should be noted that the absence of greater restrictions on the use of infrared radiation validates the option of infrared lamps as aids to drying (in addition to drying by ventilation).

In relation to the sub-system of drying by infrared radiation it was important to include more than one lamp to maximize the distribution of the emitted heat. With this, we opted for low power lamps with a high relative filament length. These enable a good positioning relative to the general overlapping of the structure of the system for drying the human body after bathing.

As seen, $600 \mathrm{~W}$ were reserved for the radiation component of the system. It was decided to include 3 infrared lamps (wavelength of $1100 \mathrm{~nm}$ (Anon n.d.)), each with $200 \mathrm{~W}$ of power. One of them located at the bottom of the subsystem (only activated in vertical mode) and the other two located at the top of the system, allowing at least two of them to be used during the drying of bedridden patients and greater heat coverage in the largest areas/drying areas such as the trunk and hair.

\section{Results and Discussion}

According to the voice of the costumer, the main concerns of potential users were:

- Safety - so this new solution eliminates the need to climb to platforms or steps, reducing the risk of fall;

- Efficiency - considering the average time of drying with towel, in the case of the elderly, was around 4 minutes;

- Comfort - since for the elderly the drying of the back with the towel is a very present and difficult problem to solve.

To an initial approach the new solution presented in this paper proposes to respond to all these concerns. Notwithstanding, it is necessary to validate this theoretical analysis with practical tests.

It will be essential to understand the extent to which the combination of infrared radiation and ventilation will improve the efficiency of the apparatus through laboratory tests.

On the future construction of the prototype some techniques will be used, in order to decrease the global costs of its production [28]. 


\section{Conclusions}

In this paper was presented a new solution to drying human body after bath. This solution was designed as a conceptual idea to a potential new tradable product.

A key aspect as justification for this project is the market space for penetration of new solutions in assistive equipment. Fundamentally because the other technological alternatives available on the market do not respond as fully to the problem as the proposed system.

The scalable potential that this area presents is significant as to the relevance that cutting-edge technology in a sector as specific as health/wellbeing can represent in the national context. The weight of technological innovation in the development of the country must be based on this type of academic research, seeking to generate versatile and marketable solutions that present distinct advantages in relation to the technological establishment.

The solution achieved anticipates the incorporation of added value compared to existing solutions. The main differentiating factor of the developed system is the drying capacity of users both lying down (in case of bedridden patients) and standing (domestic users), making possible an ambivalent and therefore versatile solution.

The operation of the new solution assembles two methods of drying (infrared radiation and ventilation), enhancing the drying efficiency.

The aim of this project was to contribute to the wellbeing of society by solving a problem through a disruptive solution.

On the one hand, mixing two drying methods present individually in other solutions marked a technological evolution, on the other hand the bet on the versatility of a larger sales volume, covering a larger market.

Next of the project, related to the laboratory test of a functional prototype, will strengthen the theoretical ideas presented on this paper.

\section{References}

[1] European Demographic Data Sheet, 2006. Available online: http://epp.eurostat.ec.europa.eu/statistics_explai ned/index.php/Population_structure_and_ageing (accessed on 09 June 2017).

[2] Leão, C.P., Soares, F., Rodrigues, H., Seabra, E., Machado, J., Farinha, P., Costa, S. "Web-assisted laboratory for control education: Remote and virtual environments" (2012) Communications in Computer and Information Science, 282 CCIS, pp. $62-72$
[3] Leão, C.P., Soares, F.O., Machado, J.M., Seabra, E., Rodrigues, H. "Design and development of an industrial network laboratory" (2011) International Journal of Emerging Technologies in Learning, 6 (Special Issue 2), pp. 21-26

[4] Pereira, F., Carvalho, V., Soares, F., Machado, J., Bezerra, K., Silva, R., Matos, D. "Development of a Medical Care Terminal for Efficient Monitoring of Bedridden Subjects", (2016) Journal of Engineering (United States), 2016, art. no. 3591059

[5] Campos, J.C., Machado, J., Seabra, E. Property patterns for the formal verification of automated production systems (2008) IFAC Proceedings Volumes (IFAC-PapersOnline), 17 (1 PART 1)

[6] Campos, J.C., Machado, J. "Pattern-based analysis of automated production systems" (2009) IFAC Proceedings Volumes (IFAC-PapersOnline), 13 (PART 1), pp. 972-977

[7] Kunz, G., Perondi, E., Machado, J. "Modeling and simulating the controller behavior of an Automated People Mover using IEC 61850 communication requirements" (2011) IEEE International Conference on Industrial Informatics (INDIN), art. no. 6034947, pp. 603608.

[8] Kunz, G., Machado, J., Perondi, E. "Using timed automata for modeling, simulating and verifying networked systems controller's specifications" (2017) Neural Computing and Applications, 28 (5), pp. 1031-1041.

[9] Campos, J.C., Machado, J. “A specification patterns system for discrete event systems analysis (2013) International Journal of Advanced Robotic Systems, 10, art. no. A315.

[10] Bruno, S., José, M., Filomena, S., Vítor, C., Demétrio, M., Karolina, B. "The conceptual design of a mechatronic system to handle bedridden elderly individuals" (2016) Sensors (Switzerland), 16 (5), art. no. 725

[11] Bezerra K., Machado J., Carvalho V., Castro M., Costa P., Matos D., Soares F. "Bath-Ambience-A Mechatronic System for Assisting the Caregivers of Bedridden People" (2017) Sensors (Switzerland), 17(6), art. no. 1156

[12] Anon. 2016. "The Body Dryer | Indiegogo." Retrieved October 15, 2016 (https://www.indiegogo.com/projects/thebody-dryer\#/).

[13] Anon. 2016. “Tornado Body Dryer." Retrieved October 15, 2016 (http://www.tornadobodydryer.com/).

[14] Anon. 2016. “Care Dryer." Retrieved October 15, 2016 (http://www.haystack-dryers.com/).

[15] CN1547446, China, 2001, International.

[16] GB2497798, Gareth David Winston, 2013, Great Britain, International.

[17] US4970736, Yasumori Koizumi, 1990, United States, International. 
[18] US5930912, Kathy Carder, 1999, United States, International.

[19] US6148539, Judith A. Hatfield; Mel E. Hatfield, 2000, United States, International.

[20] US20070039199, Allen R. Whitman, 2007, United States, International.

[21] US20160331193, Jeffry Brown; W.Garwood, 2016, United States, International.

[22] Dieter, G; Schmidt, L. 2009. Engineering Design. 4a. Nova Iorque: McGraw-Hill.

[23] Ventilnorte. 2016. "Ventilnorte | Grupos de Aspiração Ezzibox." Retrieved June 4, 2017 (http://www.ventilnorte.com/grupos-deaspiracao-ezzibox/ezzibox.html).

[24] Huang, Cunrui, Wenjun Ma, and Susan Stack. 2012. "The Hygienic Efficacy of Different HandDrying Methods: A Review of the Evidence." Mayo Clinic Proceedings 87(8):791-98.
[25] Lee, Joo-Young, Jeong-Wha Choi, and Ho Kim. 2007. "Determination of Hand Surface Area by Sex and Body Shape Using Alginate." Journal of PHYSIOLOGICAL ANTHROPOLOGY 26(4):47583. Retrieved (http://joi.jlc.jst.go.jp/IST.JSTAGE/jpa2/26.475 ?from=CrossRef).

[26] Bender, Arnold Bender; David. 1995. A Dictionary of Food and Nutrition. edited by O. U. Press. New York.

[27] Portuguesa, Norma. 1995. Norma Portuguesa.

[28] Trojanowska, J., Zywicki, K., Varela, M.L.R., Machado, J.M. (2015) "Shortening changeover time - An industrial study" 2015 10th Iberian Conference on Information Systems and Technologies, CISTI 2015, art. no. 7170373. 